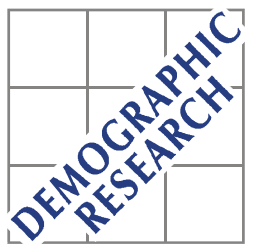

Demographic Research a free, expedited, online journal of peer-reviewed research and commentary in the population sciences published by the Max Planck Institute for Demographic Research Konrad-Zuse Str. 1, D-18057 Rostock · GERMANY www.demographic-research.org

DEMOGRAPHIC RESEARCH

VOLUME 13, ARTICLE 12, PAGES 281-300

PUBLISHED 17 NOVEMBER 2005

http://www.demographic-research.org/Volumes/Vol13/12/

DOI: 10.4054/DemRes.2005.13.12

Research Article

Unconventional approaches

to mortality estimation

Kenneth Hill

Yoonjoung Choi

Ian M. Timæus

This article is part of Demographic Research Special Collection 4, "Human Mortality over Age, Time, Sex, and Place: The $1^{\text {st }}$ HMD Symposium".

Please see Volume 13, publications 13-10 through 13-20.

(C) 2005 Max-Planck-Gesellschaft. 


\section{Table of Contents}

$\begin{array}{lll}1 & \text { Introduction } & 282\end{array}$

$2 \quad$ Methods to evaluate and adjust registered deaths 283

2.1 Application of death distribution methods to the Republic of 285

2.2 Thresholds and exclusionary principles 289

3 Alternative data collection methodologies 290

$4 \quad$ Indirect methods based on the survival of close relatives 291

$5 \quad$ Intercensal survival methods $\quad 293$

6 Conclusions 294

$7 \quad$ Acknowledgements $\quad 294$

$\begin{array}{ll}\text { References } & 295\end{array}$

$\begin{array}{ll}\text { Appendix } 1 & 298\end{array}$ 


\title{
Unconventional approaches to mortality estimation
}

\author{
Kenneth Hill ${ }^{1}$ \\ Yoonjoung Choi ${ }^{2}$ \\ Ian M. Timæus ${ }^{3}$
}

\begin{abstract}
Most developing countries do not have complete registration of deaths on which to base mortality estimates. Four broad categories of unconventional methods have been developed to provide mortality estimates in such settings. The first consists of approaches for evaluation adjustment of incompletely recorded deaths by comparison with recorded age distributions. The second consists of alternative data collection methodologies collecting information about deaths by age. The third consists of approaches based on asking respondents about the survival or otherwise of close relatives. The fourth estimates mortality from changes in age distributions, interpreting cohort attrition as mortality. Methods in the first two categories offer the greatest potential for contributing information on developing country mortality to the Human Mortality Database. Methods in the first category are illustrated here by application to data from the Republic of Korea for the second half of the $20^{\text {th }}$ century. In populations with good age reporting and little net migration, these methods work well and offer the opportunity to include developing country data in the HMD.
\end{abstract}

This article is part of Demographic Research Special Collection 4, "Human Mortality over Age, Time, Sex, and Place: The $1^{\text {st }}$ HMD Symposium". Please see Volume 13, Publications 13-10 through 13-20.

\footnotetext{
${ }^{1}$ Johns Hopkins University. E-mail: khill@jhsph.edu

2 Johns Hopkins University E-mail: ychoi@jhsph.edu

${ }^{3}$ London School of Hygiene \& Tropical Medicine. E-mail: ian.timaeus@lshtm.ac.uk
} 


\section{Introduction}

The method of choice for monitoring levels, trends and differentials of mortality (except in infancy, when the conventional Infant Mortality Rate is generally satisfactory) is to calculate occurrence/exposure (O-E) mortality rates from death counts obtained from a civil registration system $(\mathrm{O})$ and exposure estimates derived from periodic population censuses (E). However, this method of choice was used for only 14 percent of the population of the developing world in the United Nations' 2000 revision of population estimates and projections (Hill 2003) and, even for most of that 14 percent, the data required evaluation and adjustment prior to arriving at final estimates. In some regions, the situation was much worse: the method of choice was not used for any country of sub-Saharan Africa or South-Central Asia, and only in the developed world and in Latin America and the Caribbean was it used for a majority of the population of the region.

Registration of deaths is often incomplete, and even when coverage is adequate, information regarding age is often inaccurate. Census data, needed for denominators of standard rates, are also often of uncertain quality. Considerable ingenuity has been shown in the development of methods to adjust incompletely registered deaths for omission, of methods to convert indirect indicators of survivorship into standard life table measures, and of ways to collect substitute information from household surveys. However, wide differences of opinion remain about how well many of these methods and approaches perform. Uncertainty about adult mortality is substantially greater than that concerning child mortality: there is no equivalent in terms of inter-survey reliability and apparent validity for adult mortality measurement of the birth history approach to data collection concerning child mortality. Even with child mortality, however, uncertainty remains, for instance about age patterns of mortality in infancy or the relationship between mortality in infancy and that between the ages of one and five.

It has been difficult to validate the performance of many methods to measure adult mortality because there is no "gold standard." Countries with good vital registration data do not generally collect the information needed for the application of indirect methods, and their conventional data do not exhibit the magnitude of potential errors found in many developing country data sets, thus not providing a realistic test of adjustment methods.

The purpose of this paper is to help set the stage for a discussion of how developing country data sets might be incorporated into the Human Mortality Database (HMD). The key criteria for inclusion in the HMD are that mortality measures should be valid, refer to a specific time period, and represent specific age intervals. Until now, the HMD has incorporated only conventional mortality data from developed countries: registered deaths by age and sex plus periodic population counts. The data for these 
populations have been assumed to be accurate within narrow limits. As indicated above, most developing countries do not have such data, and even for those that do, evaluation and under certain circumstances adjustment are required. A variety of methods have been developed for such evaluations and for obtaining estimates of mortality in settings where no satisfactory information on deaths by age is available (see, for example, reviews by Hill (1991) for childhood and Timæus (1991c) for adulthood). In this paper we categorize the methods into four groups, roughly in descending order of similarity to the "method of choice", give a broad review of the nature of the methodologies in each category, and discuss their suitability or otherwise for contributing to the HMD.

The first category consists of approaches for evaluation and, in favourable conditions, adjustment of incompletely recorded deaths by comparison with recorded age distributions. The second category consists of alternative data collection methodologies such as sample registration systems or including questions in censuses or large household surveys about deaths in a recent reference period. The third consists of approaches based on asking respondents about the survival or otherwise of close relatives - mothers abut their children, children about their parents, and everybody about their siblings. The fourth category estimates mortality from changes in age distributions, interpreting cohort attrition as mortality.

\section{Methods to evaluate and adjust registered deaths}

If the completeness of death recording relative to population recording can be estimated, any differential in completeness can be adjusted for, unbiased death rates can be calculated, and a complete life table developed. Formal equations for population age distributions imply necessary links between the age pattern of deaths in a population and the age pattern of the surviving population. These links provide the basis for assessing the completeness of death recording by age by comparison with the age distribution of the living. However, the methods require fairly strong simplifying assumptions. Further, the methods are not useful for evaluating the completeness of recording for deaths in infancy and early childhood unless an independent estimate is available of the number of births; the methods have only proved to be of value for application to distributions of deaths post-childhood. It would be possible to assume that estimated coverage of post-child deaths would apply also to deaths in childhood, but empirically it has been observed that the coverage of child deaths by vital registration is often very different (typically worse) than the coverage of adult deaths.

All the methods that have been widely used assume that the completeness of coverage of post-child deaths is invariant with age, and evaluate completeness of death 
recording by comparing the age pattern of deaths with the age pattern of the living. The methods also require one to assume that the population is closed or, alternatively, that an adjustment can be made for the impact on the population's dynamics of migration using independently available estimates of net migration flows by age.

The simplest (and earliest) method derives from the Demographic Balancing Equation, and further assumes that the population under study is demographically stable (Brass 1975). For any open-ended age segment $a+$ of a closed population, the entry rate into the segment is equal to the growth rate of the segment plus the exit (death) rate of the segment. In a stable population, the growth rate is constant for all segments, so the entry rate and the death rate must be linearly related. If the entry rate is calculated from a population age distribution alone, any coverage error in the population data that is invariant with age cancels out, whereas the death rate, calculated from both deaths by age and population by age, will be affected by any differential coverage between population and deaths. The slope of the line relating the entry rate to the exit rate will estimate the completeness of population recording relative to death recording, and provide a potential adjustment factor for the deaths. The intercept is equal to the stable rate of population growth.

This simple method can be generalized when two or more census enumerations are available. Under such circumstances, the growth rate of each segment can be calculated from the census counts, and the assumption of stability is no longer needed. The relationship of the entry rate minus the growth rate (a residual estimate of the death rate estimated from the age distributions alone) to the death rate, segment by segment, estimates an intercept that captures any change in census coverage (assumed constant by age within each census) between the two censuses, and a slope that estimates the coverage of death recording relative to an average of the coverage of the two censuses (Hill 1987). This method we refer to as General Growth Balance or GGB.

Bennett and Horiuchi $(1981 ; 1984)$ propose an alternative way of using two censuses and a distribution of deaths by age. The age-specific growth rates for the intercensal period are used to expand the observed distribution of deaths by age to that which would have been observed for a stationary population or life table distribution. Since the life table deaths above age $a$ are equal to the life table population of exact age $a$ (since everyone dies), the ratio of expanded deaths above age $a$ to an estimate of the population aged $a$ derived from the two age distributions estimates the completeness of death recording relative to census coverage. This method we refer to as Synthetic Extinct Generations or SEG.

Applications of these two methods to data containing simulated errors (Hill 2003) indicate that the GGB method is more sensitive to age reporting errors, whereas the SEG method is much more sensitive to even slight changes in census coverage that distort the growth rates. The simulations further suggest that a two-step process, first 
applying the GGB method to estimate any change in census coverage, and then applying the SEG method after adjusting for coverage, generally gives the results closest to the truth.

The application of these methods is of potential value to the HMD for two reasons: the methods should provide a way of assessing whether data based on death registration in developing countries should be included in the HMD without adjustment, and the methods should be able to assess the quality of historical data from the $19^{\text {th }}$ century, that are already part of the HMD. The first contribution raises a pair of additional questions for the HMD: if evaluation indicates that the reporting of deaths is not complete, should an attempt be made to use the results of the methods to adjust for under-coverage, and should some threshold be decreed beyond which under-coverage is deemed too great to adjust for? We illustrate the methods with applications to a developing country, using data from the Republic of Korea covering the second half of the $20^{\text {th }}$ century.

\subsection{Application of death distribution methods to the Republic of Korea, 1955-2000}

Death distribution methods perform most satisfactorily with data from populations where age is reported with considerable accuracy. As in other East Asian countries, age reporting in the Republic of Korea is thought to be reasonably good, thanks to the traditional importance of birth year, month, date, and even hour and the 12-year cycle of "animal years" (Coale 1991). In this section, we apply the death distribution methods to data from the Republic of Korea for the period 1955-2000. A total of 10 censuses and annual deaths during each intercensal period were obtained from United Nations Demographic Yearbook series and the Korean Statistical Information System (http://kosis.nso.go.kr/). We use the two-step process: first estimating any change in census coverage using the GGB method, adjusting the census data for consistency of coverage, and then estimating the completeness of death registration relative to census coverage using the SEG method.

In order to assess goodness of fit of the methods, we examined diagnostic plots by method using data for females. Figures 1(a) and 1(b) show results for the 1955-60 period and Figures 2(a) and 2(b) present results for the 1995-2000 period. For the GGB method, the vertical scale represents the difference between the entry rate $a+$ and the growth rate $a+$, while the horizontal scale represents the observed death rate $a+$. A straight line has been fitted to the points for age segments $15+$ to $55+$ using orthogonal regression as suggested by Bhat (1990). For the SEG method, the vertical scale represents completeness of death recording $a+$ and the horizontal scale represents age segment $a+$. Age segments $5+$ to $55+$ are presented for all figures. 
Figure 1: Diagnostic plots of the death distribution methods, South Korea, Female, 1955-60

(a) The GGB method

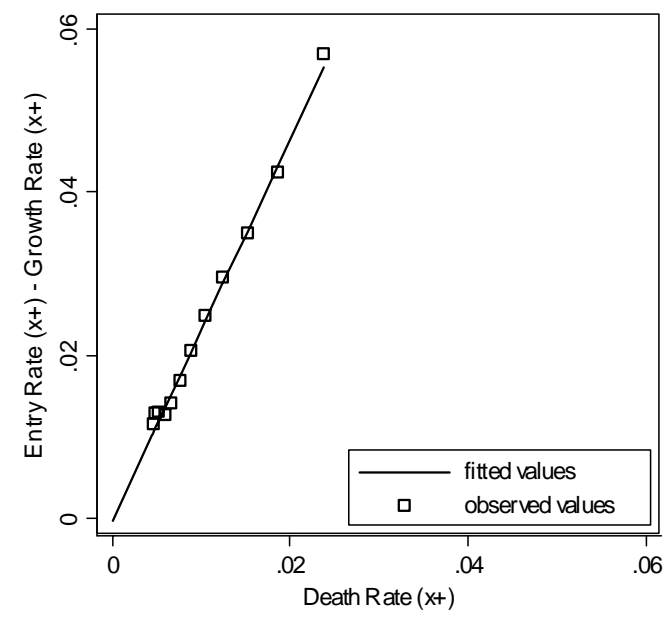

(b) The SEG method

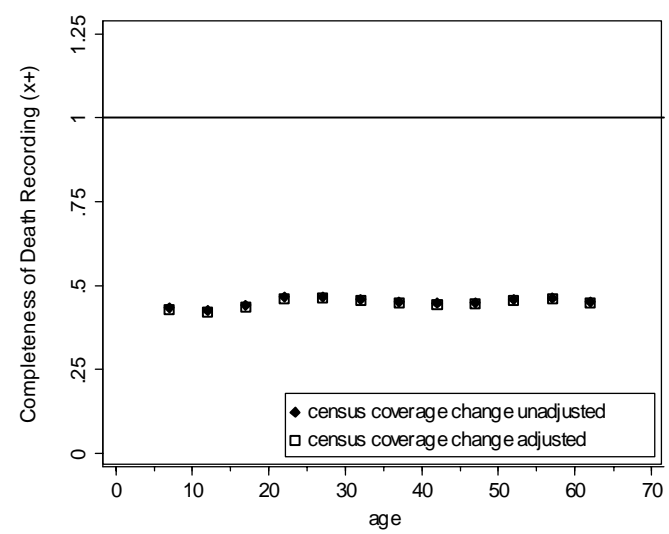


Figure 2: Diagnostic plots of the death distribution methods, South Korea, Female, 1995-2000

(a) The GGB method

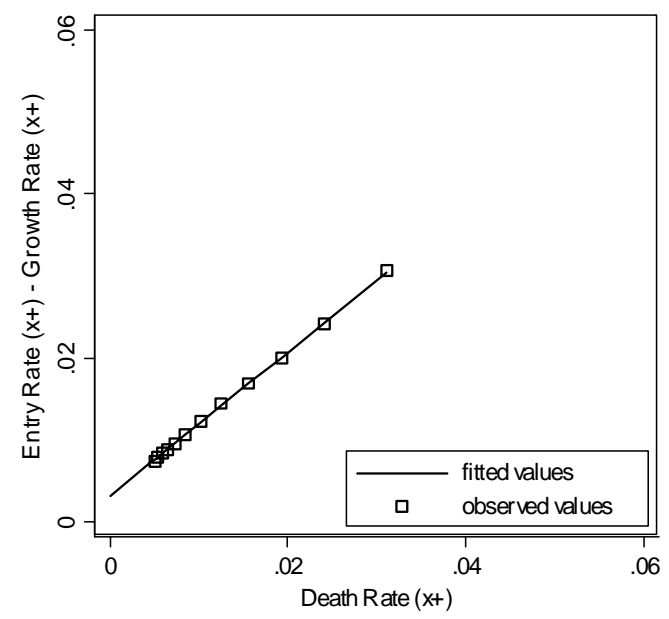

(b) The SEG method

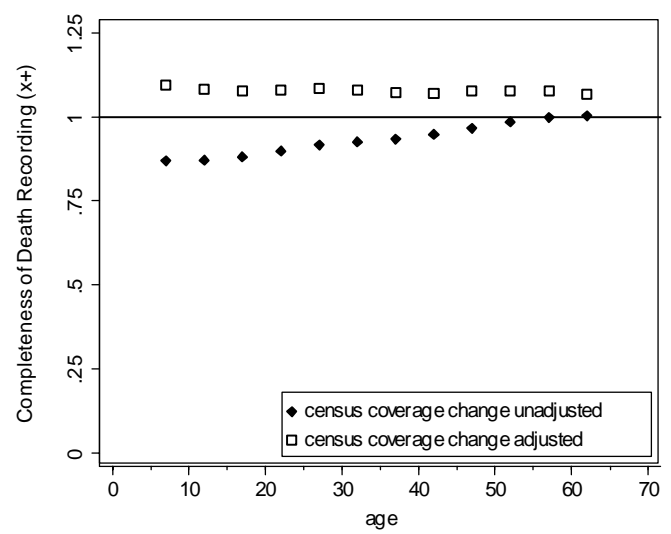


Diagnostic plots of the GGB show that the fits of the observations to a straight line are remarkably good, and improved over time. Younger age segments (points closer to the origin) are rather off of the fitted line for the period 1955-1960 (Figure 1(a)), but the fits are almost perfect for the period 1995-2000 (Figure 2(a)). This implies age reporting is exceptionally good and the assumptions of the method are met reasonably. Nevertheless, the steep slope of the fitted line in Figure 1(a), estimated to be about 2.3, indicates significant undercounting of deaths relative to population in 1955-60. On the other hand, in 1995-2000, the slope is close to 1 but the positive intercept of 0.003 indicates that population coverage declined between two censuses. Parameters of fitted lines are listed by sex and period in Appendix 1.

Plots of the GGB method indicate that, adjusted for census coverage changes, completeness of death recording is comparable across age segments for both periods. In particular, for the period 1995-2000, a decrease of about 2 percent in census coverage resulted a pattern of ascending completeness of death recording with age segments, but it was satisfactorily adjusted by the two-step process (Figure 2(b)). In addition, we again see significant improvement in completeness of death recording relative to population over time. Average completeness of death reporting for age segments $5+$ to $55+$ was about $55 \%$ lower than that of population in 1955-60. For the 1995-2000 period, however, death recording is estimated to have been 8 percent higher than population recoding in the same age segments. Table 1 summarizes estimates of the relative completeness over the nine intercensal periods, as well as probabilities of dying between 15 to $60\left({ }_{45} \mathrm{q}_{15}\right)$ implied by adjusted age-specific mortality rates. For both males and females, death recording completeness improved to a level similar to that of census completeness by the late 1970s. Adult mortality decreased dramatically during the 45-year period: ${ }_{45} \mathrm{q}_{15}$ decreased for males from 0.438 during the 1955-1960 period to 0.173 during the $1995-2000$ period, and for females from 0.302 in the earlier period to 0.066 in the most recent period. It is notable that, except for one brief reversal in the period 1970-75, mortality is estimated to have declined steadily throughout the period.

The quality of the diagnostic plots and the consistency of the adult mortality estimates in these applications suggests that the methods are working well. However, for the HMD, there is still the issue of deciding on thresholds and exclusionary principles. 
Table 1: Relative completeness of death registration and population estimates and the estimated probability of dying between 15 to 60 , South Korea, 1955-2000.

\begin{tabular}{lllllll}
\hline $\begin{array}{l}\text { Inter- } \\
\text { censal } \\
\text { period }\end{array}$ & $\begin{array}{c}\text { Completeness } \\
\text { of death } \\
\text { registration }\end{array}$ & $\begin{array}{c}\text { Completeness } \\
\text { of } 2^{\text {nd }} \text { census }\end{array}$ & $45 q 15$ & $\begin{array}{c}\text { Completeness } \\
\text { of death } \\
\text { registration }\end{array}$ & $\begin{array}{c}\text { Completeness } \\
\text { of } 2^{\text {nd }} \text { census }\end{array}$ & $45 q 15$ \\
\hline $1955-60$ & 0.46 & 0.98 & 0.438 & 0.45 & 1.00 & 0.302 \\
$1960-66$ & 0.60 & 0.98 & 0.393 & 0.50 & 0.99 & 0.288 \\
$1966-70$ & 0.85 & 1.00 & 0.331 & 0.71 & 1.00 & 0.230 \\
$1970-75$ & 0.94 & 0.99 & 0.335 & 0.77 & 1.00 & 0.240 \\
$1975-80$ & 1.06 & 1.00 & 0.314 & 0.97 & 1.00 & 0.180 \\
$1980-85$ & 1.06 & 0.99 & 0.283 & 1.06 & 0.99 & 3.133 \\
$1985-90$ & 0.99 & 0.97 & 0.264 & 0.96 & 0.99 & 0.118 \\
$1990-95$ & 1.06 & 1.02 & 0.206 & 1.19 & 1.03 & 0.074 \\
$1995-2000$ & 1.06 & 1.02 & 0.173 & 1.08 & 1.02 & 0.066 \\
\hline
\end{tabular}

\subsection{Thresholds and exclusionary principles}

In its annual compilation of demographic data, the Demographic Yearbook, the United Nations (1947-1999) classifies as "complete" data on vital events which are reported by national authorities to be 90 percent or more complete. Such a level of completeness is hardly adequate for a careful analysis of trends since, even at moderate mortality levels, for example an $e_{0}$ around 70 years, such an error would lead to overestimation of life expectancy by nearly 1.5 years. The questions facing the HMD are: should data that may be only 90 percent complete be included in the HMD at all? If yes, should an even lower cut-off be established, above which evaluation and adjustment methods may work adequately, but below which the key assumption of the adjustment methods (that the observed deaths are representative of all deaths) can not be maintained? Also, if yes, should both observed and adjusted series be reported, or should only the observed distributions be shown with a cautionary note about coverage?

We believe that it would be a missed opportunity if the HMD were to exclude all defective data from the developing world. Should a lower cut-off for coverage be implemented? Probably yes, but we do not have a single figure to offer; such a single figure may depend on the nature of the data collected, the consistency of diagnostic plots, and the likelihood that the reported distribution of deaths by age is representative 
of the total. For example, suppose that a substantial minority of the population live in rural areas and death registration is markedly less effective in rural than urban areas. In this situation, application of these methods will produce distorted results to the extent that the age distribution of the largely rural omitted deaths differs from that of the largely urban deaths that are reported.

\section{Alternative data collection methodologies}

The problem of incomplete registration of vital events has been addressed also by the development of alternative approaches to the collection of "conventional" data on deaths by age. Two are of major importance: sample registration systems, and the incorporation in censuses or very large household surveys of questions concerning deaths (by age and sex) in each household during some reference period (typically one year) before the inquiry.

The best-known sample registration system is that operated in India. The SRS was initiated by the office of the Registrar-General, India on a pilot basis in a few selected sites in 1964/5. By 1969/70 it covered 3,700 geographic units, and has almost doubled to the present. In rural areas units are villages or segments of villages, sampled from the latest population census, whereas in urban areas units are census blocks. The SRS is a dual record system consisting of the continuous enumeration of births and deaths by a resident enumerator, and an independent survey every six months. Events from the two systems are matched, and unmatched or partially matched events are reverified in the field to get an unduplicated count of births and deaths. Data from the SRS are generally thought to be of good quality; an evaluation in the late 1970s (Bhat, Preston and Dyson 1984) indicating a coverage of adult deaths of around 90 percent. Similar systems have been introduced in Bangladesh and Pakistan, but have not been subjected to the same level of evaluation as the India SRS.

The United Nations has for many years included in its recommendations for the content of population censuses that countries without complete death registration include in the census instrument questions on deaths by age and sex in each household

in the year before the census. However, concerns about the quality of the data led countries to ignore the recommendation, and few censuses after the 1960s have included such questions. The development of methods for evaluating and, if necessary, adjusting such data have rekindled interest, and China (1982, 1990, 2000 censuses), Iran (1996) and Bangladesh (large household survey 2001), to name but three, have collected the necessary data. In addition, a number of countries in Africa have tried the approach, including Senegal (1988), Benin (1992, 2002) and Zimbabwe (1992). The way the data are collected implies that some deaths will inevitably be omitted, notably 
deaths in single-person households. Deaths in households that break up after the death, perhaps because of the death, will also be missed. However, evaluation of the data for China suggests that they are of good quality, with an omission of only some 10 to 15 percent relative to the population counts (Banister and Hill 2004).

For both these approaches, the same questions arise about thresholds and exclusions as arise for incomplete civil registration. However, exclusion criteria may vary: for example, a sample registration system that records only 80 percent of deaths may not suffer from much selection bias, and the recorded deaths may be an excellent basis for calculating adjusted rates. Similarly, census questions on recent household deaths may be substantially incomplete and not suffer from severe selection bias.

\section{Indirect methods based on the survival of close relatives}

William Brass developed the first formal methods for converting indicators of mortality based on survival of close relatives into standard life table measures by adjusting for confounders. The best-known method uses mothers' reports of the number of children they had borne alive and the number who had subsequently died to estimate mortality risks in childhood (Brass 1964). Women were classified by age group as a first control for the distribution of children by exposure to the risk of dying, and the Brass method developed simple multipliers to adjust further for different age patterns of fertility. The method was subsequently refined by a number of authors (e.g. Sullivan (1972) and Trussell (1975)), and extended to estimate reference periods for each estimate and thus recent child mortality trends under conditions of steady mortality change (Coale and Trussell 1977; Feeney 1980). However, the method, though it has proved very useful over the years for estimating broad levels and trends in childhood mortality, remains an indirect method: that is, the estimates reflect averages of mortality experience across time periods and across age ranges, and provide no information about age patterns of mortality in childhood or about short-run trends. This type of information does not seem to meet the requirements of the HMD.

Encouraged by the success of Brass' indirect methodology, the early experiments, for example by the World Fertility Survey (WFS), with the use of pregnancy or birth histories to measure fertility also recorded information on the survival or otherwise of each child and, if the child had died, information on the age at death. With deaths by age and time period and exposure to risk for the same categories, age-period-specific mortality measures can be calculated from birth history data (Somoza 1980). Birth (occasionally pregnancy) histories have been widely used in survey programs, including 44 countries in the WFS, and over 110 surveys of nearly 60 countries in the Demographic and Health Surveys program. The information - deaths and exposure for 
defined time periods and age ranges - appears to meet the requirements for inclusion in the HMD. The quality of these data, however, can be poor. First, there is potential selection bias (more important in the era of HIV/AIDS than previously) since only surviving mothers report on the survival of their children. Second, retrospective reporting of age at death is not fully accurate, often with substantial "heaping" on deaths at "one year" or "12 months" that distorts age patterns of mortality in childhood. Similar errors affect early neonatal deaths and the reporting of deaths on "7 days." Third, births are not always located accurately in the past: in DHS surveys, with extensive health questions for children born in the five years before the survey, births four or five years before the survey appear to be pushed back into the sixth year before the survey to reduce interviewer work load.

The success of Brass' approach to estimating child mortality also increased interest in the possibility of estimating adult mortality from information on the survival of other relatives. Brass and Hill (1973) proposed methods for estimating life table survivorship ratios from proportions of respondents of successive five-year age groups with mother alive or father alive. The methods have been improved by several subsequent authors (Hill and Trussell 1977; Timæus 1991b, 1992; Timæus and Nunn 1997). The age group of respondents represents the survival time of the mother, so the proportion of respondents of a given age group with mother alive approximates a survivorship ratio from an average age of childbearing to that age plus the age of the respondents. The available methods model this relation using different patterns of fertility, mortality and age distribution to allow the conversion of a proportion with parent surviving into a life table survivorship ratio, controlling for the actual age pattern of childbearing. Timæus (1991a) has also developed methods for respondents whose mothers died before marriage or after marriage. Brass and Bamgboye (1981) developed a general method for estimating the reference date of estimates derived from data on survival of parents (as well as other relatives).

The estimation of adult mortality from data on survival of parents has not received the same acceptance as the estimation of child mortality from the survival of children, perhaps because of characteristics of the methods that also make them less than ideal for inclusion in the HMD: the parents of an age group of respondents will be widely distributed by age, and for respondents over age 20 will reflect exposure times over a long time period. Results are thus very broad averages over wide age ranges and time periods. The parent history, analogous to a birth history and providing information on exposure and death in defined age ranges and time periods, has not been used.

Data on survival of siblings have been fairly widely collected in recent years, particularly by DHS surveys as a basis for estimating maternal mortality. The proportion of brothers or sisters surviving by age of respondent is clearly an indicator of survivorship - approximating the probability of survival from birth to the age of the 
respondents (Hill and Trussell 1977). Improved ways of using such data have been proposed (Timæus, Zaba and Ali 2001), in particular with respect to measuring maternal mortality (Graham, Brass and Snow 1989). However, the estimates remain averages over age groups and over time periods, and not appropriate for inclusion in the HMD.

The DHS program has developed a sibling history approach to measuring adult mortality similar to the birth history approach to estimating child mortality (Rutenberg and Sullivan 1991). Information (about sex, current age if alive, age at and year of death if dead) is collected about every sibling of each respondent (limited in DHS studies to women of reproductive age) born of the same mother. Such a history permits the calculation of O-E mortality rates for defined periods and age groups, and so might qualify for inclusion in the HMD. Unfortunately, these data have several limitations. First, most DHS surveys interview too few respondents to support the calculation of age- and period-specific adult death rates without smoothing the data. Moreover, these histories will also be affected by selection bias although this may not be as severe as for the reports of mothers about their children and children about their parents. Most seriously, the histories appear to be systematically biased downwards by omissions as one moves back in time from when they were collected (Stanton, Abderrahim and Hill 2000; Timæus and Jasseh 2004 in press). If data on siblings were collected from respondents of all ages, it would be possible to apply the same evaluation (and possibly adjustment) techniques to them as described in the second section of this paper; however, no evaluation methods have been developed for the data as actually collected. Research to evaluate the quality of reports of sibling deaths across all ages is a priority.

\section{Intercensal survival methods}

The mortality risks of successive cohorts can be measured from two censuses. The survivorship ratio from the age group $a, a+5$ at the first census to the corresponding age group $a+t, a+t+5$ at the second census $t$ years later estimates the life table function ${ }_{5} L_{a+t} /{ }_{5} L_{a}$. These survivorship ratios can be compared to model life table values in order to arrive at an estimate of average post-childhood mortality, or if $t$ is a multiple of 5 , successive ratios can be chained together to come up with an estimate of a single summary indicator. This simple method seems appealing, since it offers estimates of mortality rates specific for defined cohorts and time periods. However, experience has shown that intercensal survival is very severely affected by two errors frequently present in developing country census data: changes in census coverage from one census to another (and even changes of as little as 1 percent can wreak havoc with survivorship 
ratios at younger ages) and a tendency to exaggerate the age of the elderly, which tends to give the impression of very low old age mortality.

Two census age distributions can also be used as a basis for estimating mortality using intercensal growth rates instead of intercensal survivorship ratios (Preston and Bennett 1983). Although not based on intercensal cohort survival, these methods share with intercensal survival the characteristics that the only empirical information used is two census age distributions and that the results are very sensitive to the two typical reporting errors mentioned above.

\section{Conclusions}

We have reviewed the sources of information on mortality available for the developing world in terms of their potential suitability for inclusion in the HMD, taking as the key criteria that results should be valid, refer to specific time periods and represent specific age intervals. Applying these criteria, we conclude (with some caveats, stressing the need for evaluation) that child mortality can be represented by birth history data, and that adult mortality can be represented by partially registered deaths, deaths by age recorded in censuses or very large surveys, and by information on deaths of siblings, on the condition that all these sources need to be evaluated and may need to be adjusted by the use of death distribution methods. There are a number of caveats: all these sources are potentially affected by selection bias, evaluation methods may not work perfectly (particularly in the presence of migration), and we have not been able to propose clear exclusion criteria, below which quality would be judged to be inadequate.

\section{Acknowledgements}

Paper presented at the first Human Mortality Database symposium "Human Mortality over Age, Time, Sex and Place", Max Planck Institute for Demographic Research, Rostock, Germany, 18-19 ${ }^{\text {th }}$ June, 2004. The preparation of this paper was partially supported by grant 1 P01 AG17625 to Harvard University from the National Institute of Aging, and by research infrastructure support to the Hopkins Population Center from grant 5R24 HD042854 from the National Institute of Child Health and Human Development. 


\section{References}

Banister, J. and K. Hill. 2004. "Mortality in China 1964-2000." Population Studies 58(1):55-75.

Bennett, N.G. and S. Horiuchi. 1981. "Estimating the Completeness of Death Registration in a Closed Population." Population Index 47(2):202-221.

Bennett, N. and S. Horiuchi. 1984. "Mortality Estimation from Registered Deaths in Less Developed Countries." Demography 21(2):217-233.

Bhat, P.N., S. Preston, and T. Dyson. 1984. Vital Rates in India, 1961-1981. Washington, D.C.: National Academy Press.

Bhat M. Estimating transition probabilities of age misstatement. Demography 1990; 27:149-163.

Brass, W. 1964. "Uses of Census and Survey Data for the Estimation of Vital Rates." Presented at African Seminar of Vital Statistics, Addis Ababa, 14-19th December.

- 1975. Methods for Estimating Fertility and Mortality from Limited and Defective Data. Chapel Hill: International Program of Laboratories for Population Statistics.

Brass, W. and E.A. Bamgboye. 1981. The Time Location of Reports of Survivorship: Estimates for Maternal and Paternal Orphanhood and the Ever-Widowed. London School of Hygiene \& Tropical Medicine, London.

Brass, W. and K.H. Hill. 1973. "Estimating Adult Mortality from Orphanhood." Pp. 111-123 in International Population Conference, Liège, 1973. Liège: International Union for the Scientific Study of Population.

Coale, A.J. and J. Trussell. 1977. "Estimating the Time to Which Brass Estimates Apply." Population Bulletin of The United Nations(10):87-91.

Coale AJ, Li S. The effect of age misreporting in China on the calculation of mortality rates at very high ages. Demography 1991; 28:293-301.

Feeney, G. 1980. "Estimating Infant Mortality Trends from Child Survivorship Data." Population Studies 34(1):109-128.

Graham, W., W. Brass, and R.W. Snow. 1989. "Estimating Maternal Mortality: The Sisterhood Method." Studies in Family Planning 20(3):125-135. 
Hill, K. 1987. "Estimating Census and Death Registration Completeness." Asian and Pacific Population Forum 1(3):8-13, 23-24.

-. 1991. "Approaches to the Measurement of Childhood Mortality: A Comparative Review." Population Index 57(3):368-382.

—. 2003. "Adult Mortality in the Developing World: What We Know and How We Know It." Presented at United Nations Population Division Workshop on HIV/AIDS and Adult Mortality in Developing Countries, New York, 8th-13th September.

Hill, K. and J. Trussell. 1977. "Further Developments in Indirect Mortality Estimation." Population Studies 31(2):313-334.

Preston, S.H. and N.G. Bennett. 1983. "A Census-Based Method for Estimating Adult Mortality." Population Studies 37(1):91-104.

Rutenberg, N. and J.M. Sullivan. 1991. "Direct and Indirect Estimates of Maternal Mortality from the Sisterhood Method." Presented at Demographic and Health Surveys World Conference, August 5-7, 1991, Washington, D.C., Columbia.

Somoza, J.L. 1980. Illustrative Analysis: Infant and Child Mortality in Colombia. International Statistical Institute, Voorburg, Netherlands.

Stanton, C., N. Abderrahim, and K. Hill. 2000. "An Assessment of Dhs Maternal Mortality Indicators." Studies in Family Planning 31(2):111-123.

Sullivan, J. 1972. "Models for the Estimation of the Probability of Dying between Birth and Exact Ages in Early Childhood." Population Studies 22(1):79-97.

Timæus, I.M. 1991a. "Estimation of Adult Mortality from Orphanhood before and since Marriage." Population Studies 45(3):455-472.

—. 1991b. "Estimation of Mortality from Orphanhood in Adulthood." Demography 28(2):213-227.

—. 1991c. "Measurement of Adult Mortality in Less Developed Countries: A Comparative Review." Population Index 57(4):552-568.

—. 1992. "Estimation of Adult Mortality from Paternal Orphanhood: A Reassessment and a New Approach." Population Bulletin of the United Nations 33:47-63.

Timæus, I.M. and M. Jasseh. 2004. "Adult mortality in Sub-Saharan Africa: Evidence from Demographic and Health Surveys." Demography, 41(4), 757-772. 
Timæus, I.M. and A.J. Nunn. 1997. "Measurement of Adult Mortality in Populations Affected by Aids: An Assessment of the Orphanhood Method." Health Transition Review 7(Suppl 2):23-43.

Timæus, I.M., B. Zaba, and M. Ali. 2001. "Estimation of Adult Mortality from Data on Adult Siblings." Pp. 43-66 in Brass Tacks: Essays in Medical Demography, edited by B. Zaba and J. Blacker. London: Athlone.

Trussell, T.J. 1975. "A Re-Estimation of the Multiplying Factors for the Brass Technique for Determining Childhood Survivorship Rates." Population Studies 24(1):97-108. 


\section{Appendix 1}

Parameters by the GGB method and estimates of census coverage change and of completeness of death recording relative to population by method.

Male

\begin{tabular}{|c|c|c|c|c|c|c|}
\hline \multirow{3}{*}{$\begin{array}{l}\text { Intercensal } \\
\text { period }\end{array}$} & \multicolumn{4}{|c|}{ The GGB method } & \multirow{2}{*}{\multicolumn{2}{|c|}{$\begin{array}{c}\text { The SEG method } \\
\text { Completeness of death } \\
\text { registration relative to } \\
\text { population }\end{array}$}} \\
\hline & \multirow[t]{2}{*}{ Intercept } & \multirow[t]{2}{*}{ slope } & \multirow{2}{*}{$\begin{array}{l}\text { Census } \\
\text { coverage } \\
\text { change: } \\
2^{\text {nd }} \text { to } 1^{\text {st }} \\
\text { census }\end{array}$} & \multirow{2}{*}{$\begin{array}{l}\text { Completeness } \\
\text { of death } \\
\text { registration } \\
\text { relative to } \\
\text { population }\end{array}$} & & \\
\hline & & & & & $\begin{array}{c}\text { unadjusted } \\
\text { for census } \\
\text { coverage } \\
\text { change }\end{array}$ & $\begin{array}{c}\text { adjusted } \\
\text { for census } \\
\text { coverage } \\
\text { change }\end{array}$ \\
\hline $1955-1960$ & -0.004 & 2.31 & 0.98 & 0.43 & 0.52 & 0.46 \\
\hline $1960-1966$ & -0.004 & 1.72 & 0.98 & 0.58 & 0.67 & 0.60 \\
\hline $1966-1970$ & 0.001 & 1.21 & 1.00 & 0.82 & 0.82 & 0.85 \\
\hline $1970-1975$ & -0.002 & 1.10 & 0.99 & 0.91 & 0.99 & 0.94 \\
\hline $1975-1980$ & -0.001 & 0.97 & 1.00 & 1.03 & 1.08 & 1.06 \\
\hline $1980-1985$ & -0.003 & 1.00 & 0.98 & 1.00 & 1.17 & 1.06 \\
\hline $1985-1990$ & -0.007 & 1.09 & 0.97 & 0.92 & 1.24 & 0.99 \\
\hline 1990-1995 & 0.004 & 0.94 & 1.02 & 1.06 & 0.92 & 1.06 \\
\hline $1995-2000$ & 0.004 & 0.93 & 1.02 & 1.07 & 0.92 & 1.06 \\
\hline
\end{tabular}


Parameters by the GGB method and estimates of census coverage change and of completeness of death recording relative to population by method.

\section{Female}

\begin{tabular}{|c|c|c|c|c|c|c|}
\hline \multirow{3}{*}{$\begin{array}{l}\text { Intercensal } \\
\text { period }\end{array}$} & \multicolumn{4}{|c|}{ The GGB method } & \multirow{2}{*}{\multicolumn{2}{|c|}{$\begin{array}{c}\text { The SEG method } \\
\text { Completeness of death } \\
\text { registration relative to } \\
\text { population }\end{array}$}} \\
\hline & \multirow[t]{2}{*}{ Intercept } & \multirow[t]{2}{*}{ slope } & \multirow{2}{*}{$\begin{array}{l}\text { Census } \\
\text { coverage } \\
\text { change: } \\
2^{\text {nd }} \text { to } 1^{\text {st }} \\
\text { census }\end{array}$} & \multirow{2}{*}{$\begin{array}{l}\text { Completeness } \\
\text { of death } \\
\text { registration } \\
\text { relative to } \\
\text { population }\end{array}$} & & \\
\hline & & & & & $\begin{array}{c}\text { unadjusted } \\
\text { for census } \\
\text { coverage } \\
\text { change }\end{array}$ & $\begin{array}{c}\text { adjusted } \\
\text { for census } \\
\text { coverage } \\
\text { change }\end{array}$ \\
\hline $1955-1960$ & 0.000 & 2.33 & 1.00 & 0.43 & 0.46 & 0.45 \\
\hline 1960-1966 & -0.003 & 2.10 & 0.99 & 0.48 & 0.55 & 0.50 \\
\hline 1966-1970 & 0.000 & 1.51 & 1.00 & 0.66 & 0.71 & 0.71 \\
\hline 1970-1975 & -0.001 & 1.35 & 0.99 & 0.74 & 0.81 & 0.77 \\
\hline 1975-1980 & -0.001 & 1.07 & 1.00 & 0.93 & 1.00 & 0.97 \\
\hline 1980-1985 & -0.002 & 0.98 & 0.99 & 1.02 & 1.16 & 1.06 \\
\hline 1985-1990 & -0.003 & 1.12 & 0.99 & 0.89 & 1.08 & 0.96 \\
\hline 1990-1995 & 0.005 & 0.76 & 1.02 & 1.32 & 0.97 & 1.19 \\
\hline $1995-2000$ & 0.003 & 0.87 & 1.02 & 1.15 & 0.94 & 1.08 \\
\hline
\end{tabular}


Hill, Choi \& Timaeus: Unconventional approaches to mortality estimation 